\title{
Prognostic impact of the preoperative hemoglobin A1c levels in patients with gastric cancer surgery depends on postoperative complications
}

\author{
Jun Shibamoto ${ }^{1} \cdot$ Katsutoshi Shoda $^{1} \cdot$ Takeshi Kubota $^{1} \cdot$ Toshiyuki Kosuga $^{1} \cdot$ Hidemasa Kubo $^{1} \cdot$ Takuma Ohashi $^{1}$. \\ Hiroki Shimizu ${ }^{1}$. Tomohiro Arita ${ }^{1}$. Yusuke Yamamoto ${ }^{1}$ - Hirotaka Konishi ${ }^{1} \cdot$ Ryo Morimura $^{1} \cdot$ Atsushi Shiozaki $^{1}$. \\ Yoshiaki Kuriu ${ }^{1} \cdot$ Hisashi Ikoma ${ }^{1} \cdot$ Hitoshi Fujiwara ${ }^{1} \cdot$ Kazuma Okamoto $^{1} \cdot$ Eigo Otsuji $^{1}$
}

Received: 15 May 2020 / Accepted: 27 July 2020 / Published online: 8 August 2020

(c) The Author(s) 2020

\begin{abstract}
Purpose The long-term prognostic impact of the hemoglobin A1c levels has not yet been evaluated in patients with gastric cancer. The present study investigated the clinical significance of the hemoglobin A1c levels in patients with gastric cancer. Methods We enrolled 294 patients with stage II, III, or IV gastric cancer who underwent gastrectomy. The patients were divided into high preoperative hemoglobin A1c $(>6.0 \%)$ and low preoperative hemoglobin A1c $(\leq 6.0 \%)$ groups.

Results In patients with stage III gastric cancer with severe postoperative complications, the high preoperative hemoglobin A1c group had a significantly worse prognosis than the low preoperative hemoglobin A1c group $(p=0.0409)$. In patients without severe postoperative complications, the high preoperative hemoglobin A1c group had a significantly favorable prognosis compared with the low preoperative hemoglobin A1c group $(p=0.0348)$.

Conclusion The prognosis of patients with stage III gastric cancer having high preoperative hemoglobin A1c levels greatly depended on the presence or absence of postoperative complications. To avoid postoperative complications, optimal perioperative management and personalized treatments are critical, particularly for these patients.
\end{abstract}

Keywords Gastric cancer $\cdot$ Hemoglobin A1c $\cdot$ Prognosis $\cdot$ Postoperative complications

\section{Introduction}

Gastric cancer (GC) is the fifth-most frequently occurring malignancy, and it is the third-leading cause of cancerrelated deaths worldwide [1]. Despite advances in surgical techniques, postoperative management, and treatment strategies, the long-term prognosis has not significantly improved, which remains a major challenge to human health [2].

In the past several decades, the increased incidence of lifestyle-related diseases, such as diabetes mellitus (DM), cardiovascular disease (CVD), and hyperlipidemia, has made postoperative health care more challenging and complicated. DM is reported to be associated with the risk of

Takeshi Kubota

tkubot@koto.kpu-m.ac.jp

1 Division of Digestive Surgery, Department of Surgery, Kyoto Prefectural University of Medicine, 465 Kawaramachi Hirokoji Kajii-cho, Kamigyo-ku, Kyoto 602-8566, Japan postoperative complications and adverse cancer outcomes; a systematic review and several reports have suggested that DM or hyperglycemia is associated with an adverse overall survival (OS) and the disease-free survival in patients with solid tumors [3-6]. Moreover, postoperative complications following gastrectomy have recently been determined to be one of the factors associated with a poor prognosis of patients with GC because of either the postoperative systemic inflammatory response or host immunosuppression [7-9]. On the other hand, gastrectomy could improve type 2 DM in patients [10,11]. Therefore, the blood glucose levels may have different implications in patients with GC who undergo gastrectomy.

Hemoglobin A1c (HbA1c) can reflect the glucose metabolism over the past $\sim 3$ months; therefore, it is widely accepted as gold-standard diagnostic marker for DM [12]. Although DM or poor postoperative glycemic control is reported to be a risk factor for short-term postoperative complications in patients with cancer [5, 13], the longterm prognostic impact of hyperglycemia or hypoglycemia 
remains debatable. Furthermore, the long-term prognostic impact of the HbA1c levels has not yet been evaluated in patients with GC.

This study investigated the clinical significance of the $\mathrm{HbA1c}$ levels in patients with GC by examining the relationship between the preoperative and postoperative $\mathrm{HbAlc}$ levels and the clinical outcomes according to the pathological stage.

\section{Methods}

\section{Patients}

Between January 2008 and May 2016, patients with stage II, III, or IV GC underwent gastrectomy at the Kyoto Prefectural University of Medicine Hospital, Japan. Patients whose preoperative HbA1c levels were not measured were excluded. For the remaining patients whose preoperative HbA1c levels were measured at approximately 4 weeks before gastrectomy, all measured $\mathrm{HbA} 1 \mathrm{c}$ levels were converted to National Glycohemoglobin Standardization Program levels using the conversion formula [14].

The patients were divided into two groups, namely high preoperative $\mathrm{HbAlc}(\mathrm{HbAlc}>6.0 \%)$ and low preoperative HbA1c (HbA1c $\leq 6.0 \%)$ groups. The cutoff value was $6.0 \%$, defined according to previous studies [10, 15-17]. Between the two groups, we investigated the correlation between the preoperative HbA1c levels and postoperative clinical outcomes including the prognosis according to pathological stage. Furthermore, we analyzed the preoperative and postoperative dynamics in HbA1c levels after gastrectomy. Postoperative complications were evaluated based on the Clavien-Dindo classification [18], and Clavien-Dindo classifications III, IV, and V were defined as "severe postoperative complications". Pathological staging was performed using the 8th Union for International Cancer Control tumor, nodes, and metastases staging [19].

Postoperatively, for the first 2 years, all patients were followed up every 3-6 months, and the follow-up was continued for at least 5 years. Patients who were lost during follow-up were censored at the date of last contact/follow-up. Follow-up evaluation included physical examination, blood investigation, computed tomography (CT), and gastroscopy. Recurrence was confirmed by imaging, typically with CT, and histologically, if possible, via surgical biopsy, needle biopsy, or appropriate fluid cytology.

All procedures were performed in accordance with the Declaration of Helsinki of 1964 and later versions, and the ethical standards of the responsible committees on human experimentation, both institutional (approval no. ERB-C1327 ) and national. Informed consent or a substitute was obtained from all patients prior to inclusion in the study.

\section{Statistical analysis}

The statistical analysis was performed using s JMP software program version 10 (SAS Institute, Cary, NC, USA). Fisher's exact probability test and the Chi-square test were used to compare categorical variables between the two groups, whereas nonparametric tests (Mann-Whitney $U$, Wilcoxon signed rank, and Kruskal-Wallis) were used for subgroup comparisons. OS and cancer-specific survival (CSS) were calculated using the Kaplan-Meier analysis, with the gastrectomy date as the starting point, and differences in survival were measured using the log-rank test. Univariate and multivariate analyses were performed using the Cox proportional hazards model. All statistical tests except for the paired tests were two-sided. $p<0.05$ was considered to be statistically significant.

\section{Results}

Overall, 306 patients with stage II, III, or IV GC underwent gastrectomy at our university hospital. Of these, 12 patients whose preoperative $\mathrm{HbA} 1 \mathrm{c}$ levels were not measured were excluded. Finally, 294 patients with primary GC who underwent gastrectomy with D1 plus or D2 lymph node dissection were enrolled. Curative gastrectomy (R0) was performed for 245 patients with stage II and III GC, whereas palliative gastrectomy was performed for 49 patients with stage IV GC.

\section{Clinicopathological characteristics}

Table 1 shows the association between the patients' clinicopathological characteristics and their preoperative HbA1c levels. We found no significant difference in age, sex, and pathological backgrounds between the high and low preoperative HbA1c groups; however, the high preoperative HbA1c group had a higher body mass index $(p<0.0001)$ and required a longer operation time $(p=0.0281)$ than the low preoperative HbA1c group. Of the 294 patients, 35 (12\%) developed severe postoperative complications that required surgical, endoscopic, or radiological intervention. The rate of severe postoperative complications in the high preoperative $\mathrm{HbA} 1 \mathrm{c}$ group was significantly higher than that in the low preoperative $\mathrm{HbA1c}$ group $(p=0.0455)$.

\section{Postoperative clinical outcomes}

Figure 1 shows the prognostic impact of the preoperative HbA1c levels in patients with GC according to the pathological stage. The high preoperative HbA1c group had a significantly poor prognosis in patients with stage IV GC, 
Table 1 Association between the clinicopathological characteristics and the preoperative HbA1c levels $(n=294)$

\begin{tabular}{|c|c|c|c|}
\hline Variable & Preoperative $\mathrm{HbA} 1 \mathrm{c}>6.0 \%$ & Preoperative $\mathrm{HbA} 1 \mathrm{c} \leq 6.0 \%$ & $p$ value \\
\hline Total & 73 & 221 & \\
\hline Age (years), median (range) & $70(48-85)$ & $67(29-94)$ & 0.1022 \\
\hline Sex & & & 0.1067 \\
\hline Male & 55 & 144 & \\
\hline Female & 18 & 77 & \\
\hline Body mass index $\left(\mathrm{kg} / \mathrm{m}^{2}\right)$, median (range) & $23.5(16.3-30.9)$ & $21.3(15.6-31.6)$ & $<0.0001$ \\
\hline Neoadjuvant chemotherapy & & & 0.8768 \\
\hline Present & 5 & 14 & \\
\hline Absent & 68 & 207 & \\
\hline Preoperative therapy for diabetes mellitus & & & $<0.0001$ \\
\hline Oral & 26 & 3 & \\
\hline Insulin & 4 & 0 & \\
\hline Oral and insulin & 3 & 0 & \\
\hline Absent & 40 & 218 & \\
\hline Operation time (min), median (range) & $270(60-583)$ & $236(49-626)$ & 0.0281 \\
\hline Blood loss during surgery $(\mathrm{mL})$, median (range) & $250(5-2482)$ & $226(0-2290)$ & 0.1560 \\
\hline Complication & & & 0.0455 \\
\hline No complication & 44 & 163 & \\
\hline Clavien-Dindo classification I/II & 15 & 37 & \\
\hline Clavien-Dindo classification III/IV/V & 14 & 21 & \\
\hline Tumor depth $\mathrm{h}^{\mathrm{a}, \mathrm{b}}$ & & & 0.3047 \\
\hline $\mathrm{T} 1 / 2$ & 15 & 34 & \\
\hline $\mathrm{T} 3 / 4$ & 58 & 187 & \\
\hline Lymph node metastasis ${ }^{\mathrm{a}, \mathrm{b}}$ & & & 0.6552 \\
\hline Negative & 17 & 46 & \\
\hline Positive & 56 & 175 & \\
\hline Stage $\mathrm{a}^{\mathrm{a}}$ & & & 0.9975 \\
\hline II & 30 & 90 & \\
\hline III & 31 & 94 & \\
\hline IV & 12 & 37 & \\
\hline
\end{tabular}

Significant values are given in boldface

HbAlc hemoglobin A1c

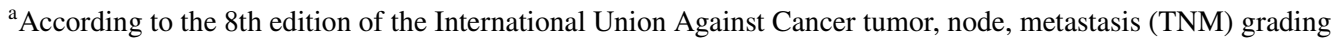

${ }^{\mathrm{b}}$ Pathological stage

although we found no significant difference between the two groups in patients with stage II or III GC (Fig. 1).

The subgroup analysis of the OS rates of patients with stage III GC according to the presence or absence of severe postoperative complications (Fig. 2a, b) showed that in patients with stage III GC with severe postoperative complications, the high preoperative HbA1c group had a significantly worse prognosis than the low preoperative HbA1c group ( $p=0.0409)$. In patients without severe postoperative complications, the high preoperative HbA1c group had a significantly better prognosis than the low preoperative HbA1c group $(p=0.0348)$. The analysis of the CSS rates of patients with stage III GC according to the presence or absence of severe postoperative complications, although not significant, showed similar results and tendency (Fig. 2c, d). In patients with stage III GC without severe postoperative complications, the high preoperative $\mathrm{HbA} 1 \mathrm{c}$ group tended to have a better prognosis than the low preoperative HbA1c group, whereas in patients with severe postoperative complications, the high preoperative $\mathrm{HbA} 1 \mathrm{c}$ group tended to have a worse prognosis than the low preoperative $\mathrm{HbA} 1 \mathrm{c}$ group ( $p=0.0655$ and 0.3032 , respectively).

Table 2 shows the results of the Cox proportional hazard model in patients with stage III GC without severe postoperative complications. High preoperative $\mathrm{HbA} 1 \mathrm{c}$ levels were significantly associated with a better prognosis in patients with stage III GC (hazard ratio $[\mathrm{HR}]=0.43 ; 95 \%$ confidence interval $[\mathrm{CI}]=0.16-0.94 ; p=0.0319)$. 
Fig. 1 Overall survival in patients with gastric cancer Kaplan-Meier curves for overall survival rates of patients with gastric cancer according to preoperative hemoglobin $\mathrm{A} 1 \mathrm{c}$ levels in stage II (a), stage III (b), and stage IV (c) gastric cancer a

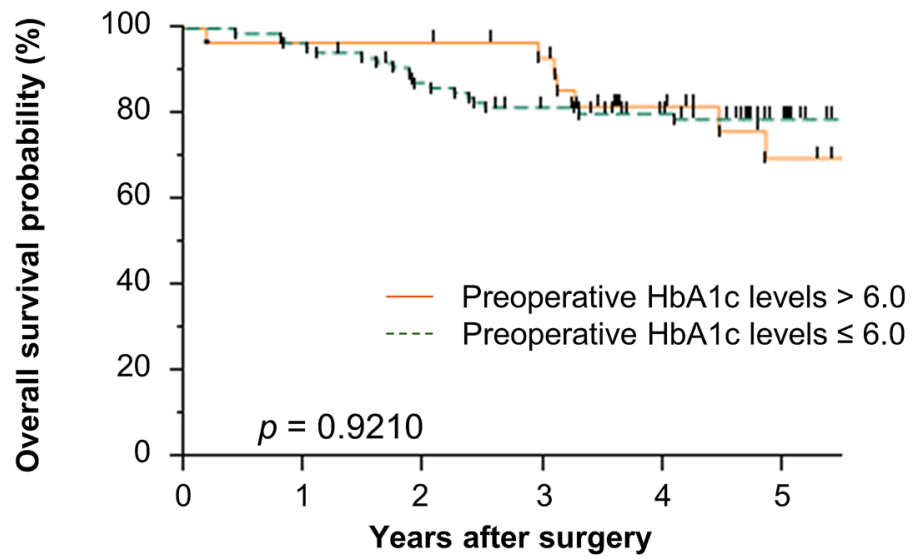

Patients at risk

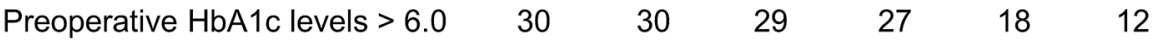

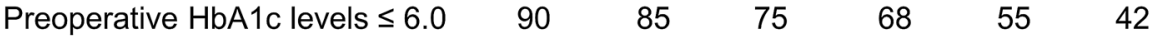

b
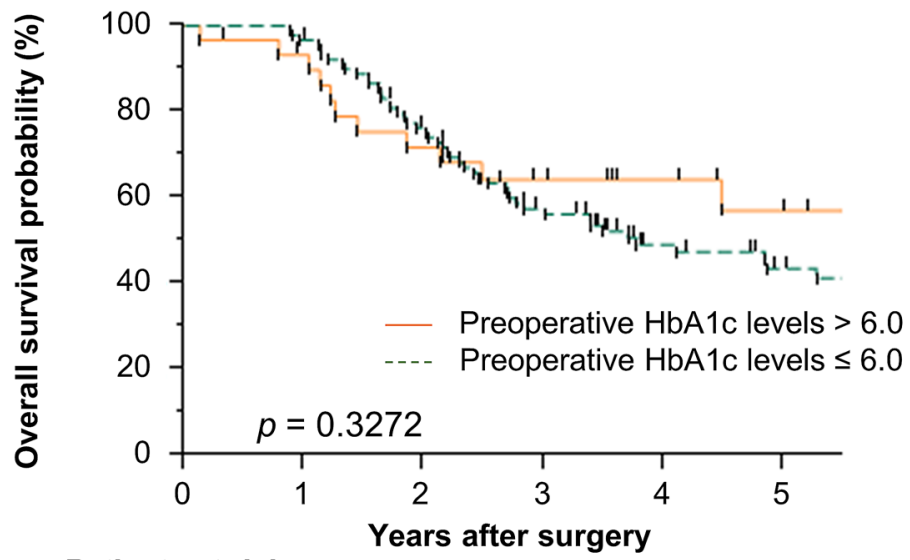

Patients at risk

$\begin{array}{lllllll}\text { Preoperative HbA1c levels }>6.0 & 31 & 26 & 20 & 15 & 11 & 8 \\ \text { Preoperative HbA1c levels } \leq 6.0 & 94 & 87 & 66 & 46 & 29 & 21\end{array}$

C

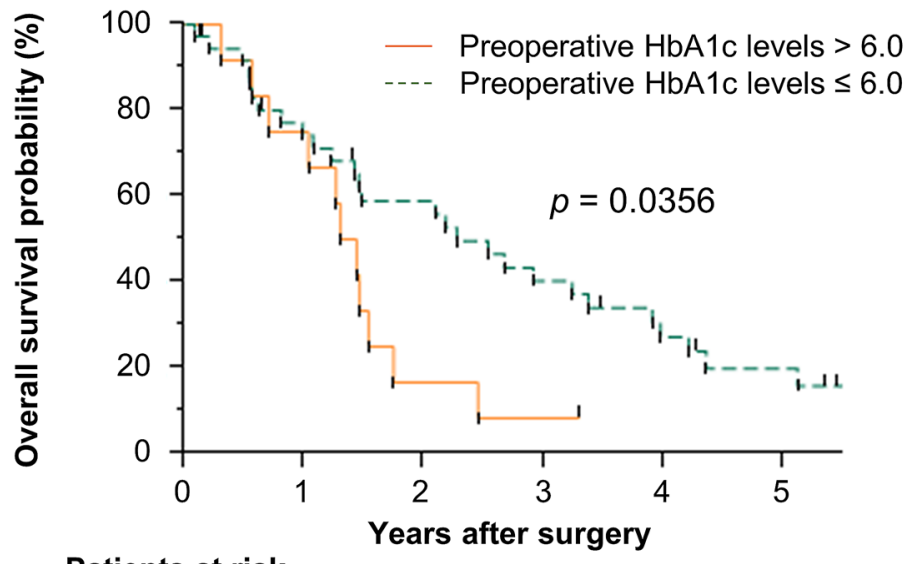

Patients at risk

$\begin{array}{lcccccc}\text { Preoperative HbA1c levels }>6.0 & 12 & 9 & 3 & 1 & 0 & 0 \\ \text { Preoperative HbA1c levels } \leq 6.0 & 37 & 26 & 19 & 14 & 9 & 5\end{array}$


Fig. 2 Overall survival and cancer specific survival in patients with stage III gastric cancer. Overall survival rates of patients with stage III gastric cancer according to preoperative hemoglobin A1c levels without (a) and with (b) severe postoperative complications. Cancer specific survival rates of patients with stage III gastric cancer according to preoperative hemoglobin A1c levels without (c) and with (d) severe postoperative complications

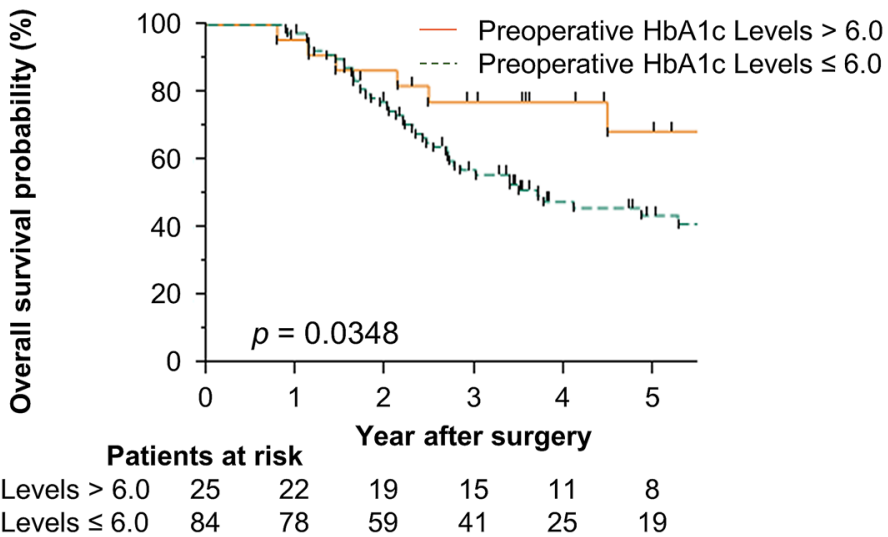

b

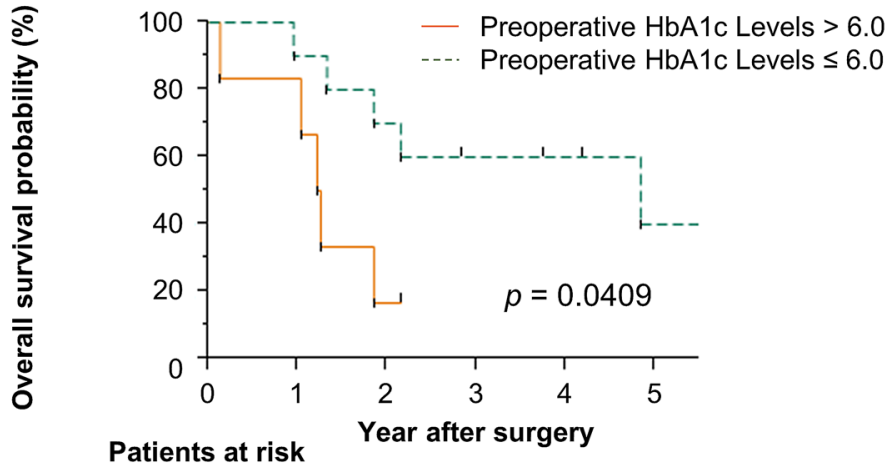

C

$\begin{array}{lllllll}\text { Preoperative HbA1c Levels }>6.0 & 25 & 22 & 19 & 15 & 11 & 8 \\ \text { Preoperative HbA1c Levels } \leq 6.0 & 84 & 78 & 59 & 41 & 25 & 19\end{array}$

Patients at risk

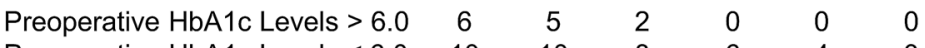

Preoperative HbA1c Levels $\leq \begin{array}{lllllll}6.0 & 10 & 10 & 8 & 6 & 4 & 3\end{array}$

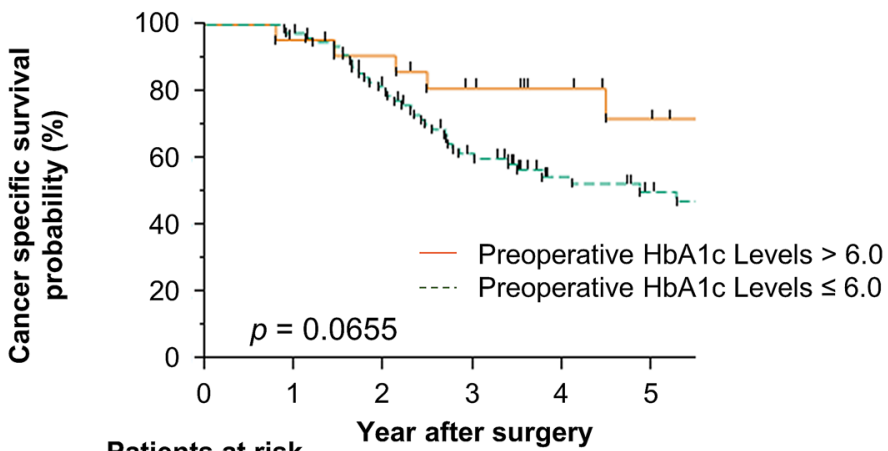

Patients at risk

$\begin{array}{lllllll}\text { Preoperative HbA1c Levels }>6.0 & 25 & 22 & 19 & 15 & 11 & 8\end{array}$

$\begin{array}{lllllll}\text { Preoperative HbA1c Levels } \leq 6.0 & 84 & 78 & 59 & 41 & 25 & 19\end{array}$

d

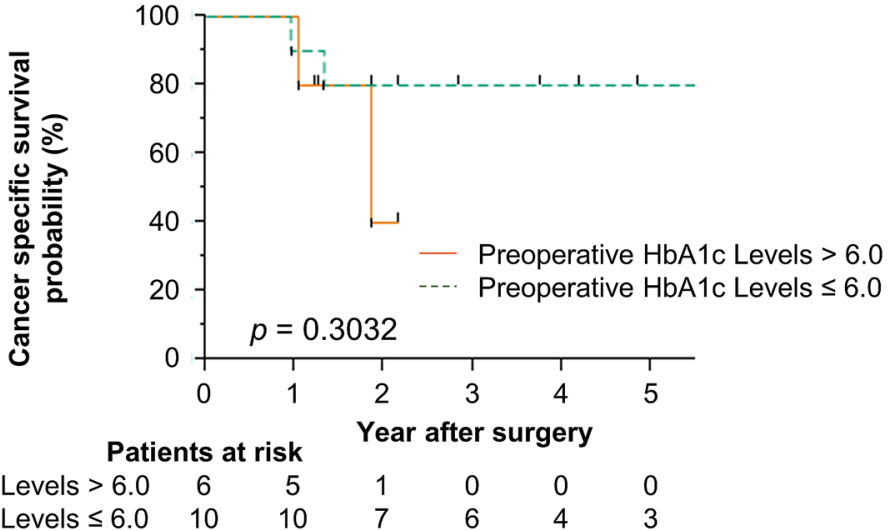


Table 2 The Cox proportional hazard regression analysis for overall survival in patients with stage III gastric cancer without severe postoperative complications

\begin{tabular}{|c|c|c|c|c|c|}
\hline \multirow[t]{2}{*}{ Variable } & \multirow[t]{2}{*}{$n$} & \multirow{2}{*}{$\begin{array}{l}\text { Univariate } \\
p \text { value }\end{array}$} & \multicolumn{3}{|c|}{ Multivariate } \\
\hline & & & $p$ value & HR & $(95 \% \mathrm{CI})$ \\
\hline Total & 109 & & & & \\
\hline Age (years) & & 0.3168 & & & \\
\hline$<70$ & 58 & & & & \\
\hline$\geq 70$ & 51 & & & & \\
\hline Body mass index $\left(\mathrm{kg} / \mathrm{m}^{2}\right)$ & & 0.3588 & & & \\
\hline$<25.0$ & 91 & & & & \\
\hline$\geq 25.0$ & 18 & & & & \\
\hline Neoadjuvant chemotherapy & & 0.6721 & & & \\
\hline Present & 6 & & & & \\
\hline Absent & 103 & & & & \\
\hline Operation time (min) & & 0.5716 & & & \\
\hline$<240$ & 53 & & & & \\
\hline$\geq 240$ & 56 & & & & \\
\hline Blood loss (mL) & & 0.4549 & & & \\
\hline$<250$ & 59 & & & & \\
\hline$\geq 250$ & 50 & & & & \\
\hline Preoperative HbA1c level (\%) & & 0.0348 & 0.0319 & 0.43 & $(0.16-0.94)$ \\
\hline$\leq 6.0$ & 84 & & & & \\
\hline$>6.0$ & 25 & & & & \\
\hline Postoperative chemotherapy & & 0.6713 & & & \\
\hline Present & 83 & & & & \\
\hline Absent & 26 & & & & \\
\hline Stage ${ }^{a, b}$ & & $<0.0001$ & $<0.0001$ & 3.75 & $(2.03-6.70)$ \\
\hline IIIA/IIIB & 91 & & & & \\
\hline IIIC & 18 & & & & \\
\hline
\end{tabular}

Significant values are given in boldface

$H R$ hazard ratio, $C I$ confidence interval, $H b A l c$ hemoglobin A1c

${ }^{a}$ According to the 8th edition of the International Union Against Cancer tumor, node, metastasis (TNM) grading

${ }^{\mathrm{b}}$ Pathological stage

\section{Without any preoperative therapy for diabetes mellitus}

We investigated OS rates of 109 patients with stage III GC without any preoperative therapy for DM. Similar to the entire cohort, without severe postoperative complications, the high preoperative HbA1c group had a significantly better prognosis than the low preoperative HbA1c group, whereas in patients with severe postoperative complications, the high preoperative $\mathrm{HbA} 1 \mathrm{c}$ group tended to have a worse prognosis than the low preoperative HbA1c group $(p=0.0458$ and 0.0857).

\section{Preoperative and postoperative dynamics of $\mathrm{HbA1c}$ levels}

A comparison of the preoperative and postoperative $\mathrm{HbA} 1 \mathrm{c}$ levels in patients with stage III GC with and without severe postoperative complications (Fig. 3) showed a significant decrease in the $\mathrm{HbA} 1 \mathrm{c}$ levels postoperatively in 46 patients without severe postoperative complications, but not in 9 patients with severe postoperative complications ( $p=0.0492$ and 0.4792 , respectively). Further, $55.0 \%$ of patients with stage III GC without severe postoperative complications in the high preoperative HbA1c group had improved to normal HbA1c levels postoperatively. In addition, $41.9 \%$ of patients with stage III GC in the low preoperative HbA1c group had shown a decrease in the postoperative $\mathrm{HbA} 1 \mathrm{c}$ levels $(\mathrm{HbA} 1 \mathrm{c}<5.4 \%)$.

\section{Discussion}

The present study revealed a paradoxical correlation between the preoperative $\mathrm{HbA} 1 \mathrm{c}$ levels and long-term outcomes in patients with GC who underwent gastrectomy. In patients 
Fig. 3 Comparison of preoperative and postoperative hemoglobin A1c levels. Comparison of preoperative and postoperative hemoglobin A1c levels in 46 patients with stage III gastric cancer without severe postoperative complications (top) and 9 patients with severe postoperative complications
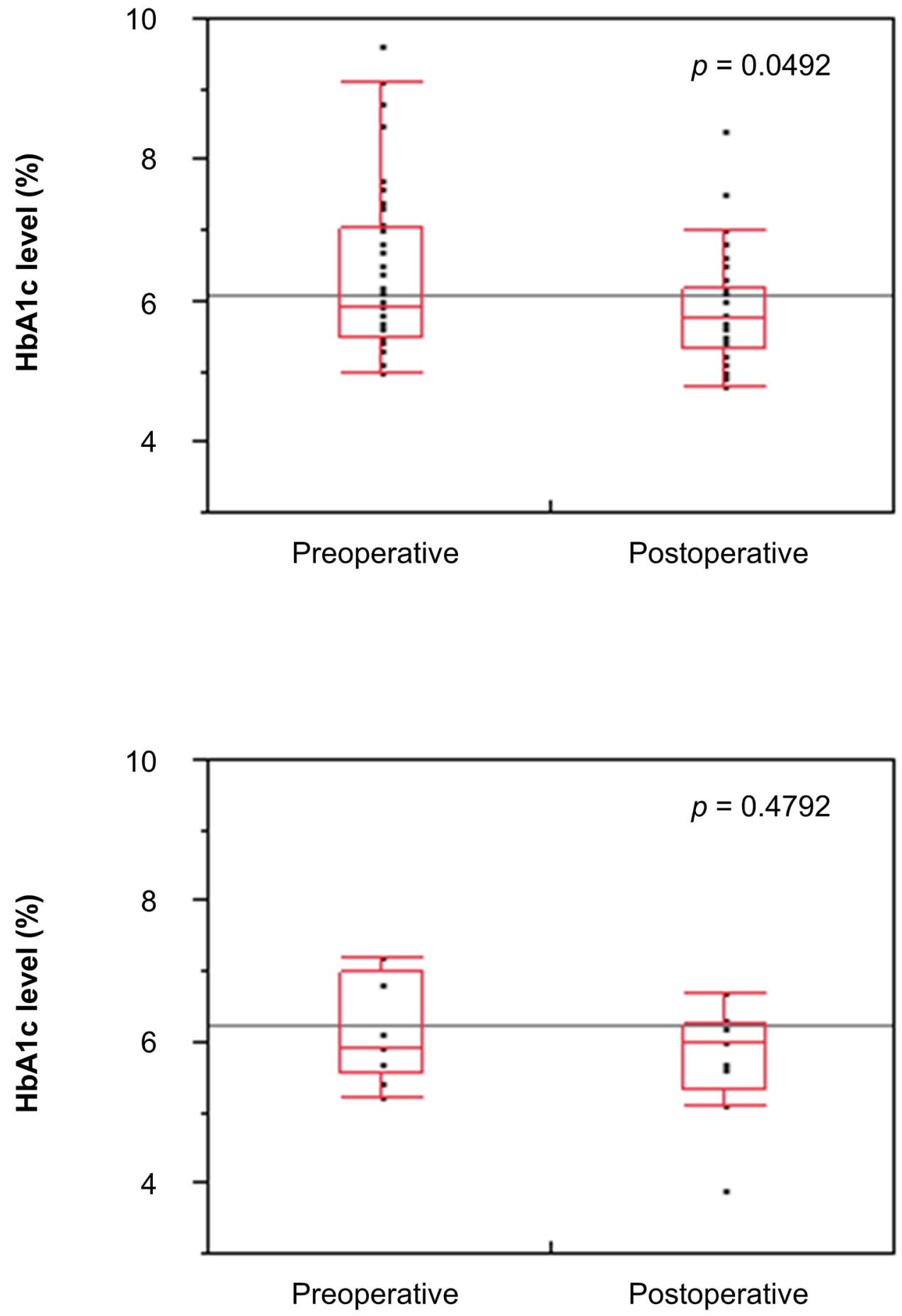

with stage III GC with severe postoperative complications, the high preoperative $\mathrm{HbA} 1 \mathrm{c}$ group had a worse prognosis than the low preoperative $\mathrm{HbA} 1 \mathrm{c}$ group, whereas in patients with stage III GC without severe postoperative complications, the high preoperative $\mathrm{HbA} 1 \mathrm{c}$ group had a significantly better prognosis than the low preoperative HbA1c group. In addition, we observed a similar tendency for patients without any preoperative therapy for DM. Similar results were not observed in patients with stage II GC, because these patients had a favorable prognosis regardless of the preoperative HbA1c levels. In patients with stage IV GC, the high preoperative HbA1c group had a significantly poor prognosis. The results suggested that hyperglycemic patients with residual cancer, such as stage IV GC, have a worse prognosis or that conversely advanced cancers affect their glucose metabolism by increasing insulin resistance [20]. Although it was 
difficult to clarify the process of the paradoxical correlation between preoperative $\mathrm{HbA} 1 \mathrm{c}$ levels and long-term outcomes in patients with stage III GC, we believe that hyperglycemia, inflammation, and gastrectomy might have been associated with the process.

It is widely known that high $\mathrm{HbA} 1 \mathrm{c}$ levels and hyperglycemia are related to adverse outcomes in surgical patients [21]. High HbA1c levels tend to be poor postoperative blood glucose control, prolonging postoperative hyperglycemia and leading to a high complication rate [17]. Postoperative hyperglycemia is associated with postoperative morbidity and mortality [22, 23] even in nondiabetic patients [24]. In our entire cohort, patients with high preoperative $\mathrm{HbA} 1 \mathrm{c}$ levels had a significantly higher postoperative complication rate than those with low preoperative HbA1c levels. In general, hyperglycemia leads to body weight increase, adiposity, and general malaise caused by increased blood insulin levels. Obesity is also associated with hyperglycemia, endocrine signals, and chronic inflammation. Therefore, patients with hyperglycemia get caught up in this vicious cycle that creates favorable microenvironments in cancer cells, leading to further abdominal inflammation and malignant cell growth [25]. Our result that the CSS rates in patients with stage III GC were similar to the OS rates might imply that postoperative hyperglycemia and prolonged inflammation have a negative impact on cancer cells. Because glucose uptake and glycolysis are accelerated in cancer cells, hyperglycemia might affect their intracellular metabolism and lead to the production of inflammatory cytokines, and the systemic inflammatory responses caused might facilitate the growth and invasion of cancer cells [26-28]. Furthermore, postoperative inflammation triggers the development and sustenance of hyperglycemia by inducing insulin resistance and accelerating gluconeogenesis [29]. This description might be supported by the result of preoperative and postoperative dynamics of HbA1c levels in patients with stage III GC with and without severe postoperative complications in the present study, wherein $\mathrm{HbAlc}$ levels in patients with complication tended not to decrease postoperatively. Thus, high $\mathrm{HbA} 1 \mathrm{c}$ levels or postoperative hyperglycemia might lead to postoperative complications, intra-abdominal inflammation, and eventually poor long-term outcomes.

However, with regard to gastrectomy, preoperative hyperglycemia or high HbA1c levels do not necessarily lead to a poor prognosis in patients with GC, because postoperative glucose levels decline on average after gastrectomy. There are several studies focusing on the glucose levels before and after bariatric surgery or gastrectomy, which resulted in a remarkable improvement in obesity and DM [11, 30, 31]. Schauer et.al [11] reported that patients who underwent gastrectomy had favorable glycemic control while using fewer diabetes medications and had a significant decrease in $\mathrm{HbA1c}$ levels. Thus, high preoperative $\mathrm{HbA1c}$ group might maintain appropriate postoperative glucose levels following gastrectomy if there are no complications, and the improvement in obesity and glycemic control might lead to suppression of chronic inflammation and favorable longterm outcomes. In patients with stage III GC without severe postoperative complications, the high preoperative $\mathrm{HbA} 1 \mathrm{c}$ group had a significantly favorable prognosis compared with the low preoperative $\mathrm{HbA} 1 \mathrm{c}$ group; however, preoperative therapy for DM is necessary because DM is associated with an increased risk of postoperative complications and adverse cancer outcomes [3-6]. In contrast, lower HbA1c levels are known to have a negative effect on patients. Goto et al. [32] showed that low the HbA1c levels are also associated with a higher risk of CVD. Although there was no significant difference in this study, a previous study reported that low pretreatment $\mathrm{HbA} 1 \mathrm{c}$ levels might be associated with a poor prognosis for patients with esophageal cancer [33]. Therefore, the $\mathrm{HbA} 1 \mathrm{c}$ levels are required to be within the normal range.

Postoperative complications lead to a poor prognosis of patients with GC [7, 34, 35]. Age, DM, liver cirrhosis, invasion of neighboring organs, combined resection, intraoperative transfusion, malnutrition, Billroth II reconstruction, surgical experience, and operation time were reported as risk factors of postoperative complications after gastrectomy [36]. Poor glycemic control is a widely known risk factor of postoperative complications [37]. In the present study, the postoperative complication rate of patients with low preoperative $\mathrm{HbA1c}$ levels was lower than that of patients with high preoperative HbA1c levels. However, a subgroup analysis in the group without postoperative complications showed that the low preoperative HbA1c group had a worse prognosis than the high preoperative HbA1c group, which might imply that the postoperative blood glucose levels decrease further thus leading to hypoglycemia in the low preoperative HbA1c group. Therefore, the management of postoperative hypoglycemia is also required for the patients with low preoperative HbA1c levels. Moreover, we have to make unwavering efforts during surgery to avoid postoperative complications by developing surgical techniques and devices (e.g., laparoscopy, robot, and surgical instruments), nutrition therapy, and optimal perioperative management especially for patients with high preoperative HbA1c levels.

The present study is associated with some limitations. First, it was a retrospective single-center study, and the study cohort was relatively small sample size. Second, we evaluated only the preoperative HbA1c levels, without considering the fasting blood glucose or perioperative serum glucose levels. We could not investigate the postoperative $\mathrm{HbA1c}$ levels in patients with low preoperative $\mathrm{HbA1c}$ levels because of the unavailability of data details. In addition, there was some bias in this cohort with regard to the $\mathrm{HbA} 1 \mathrm{c}$ levels of patients that were within a relatively acceptable 
range. Thus, the preliminary findings of the present study should be validated in a larger patient cohort and accumulation of cases with systematical management would be required to address these limitations.

In summary, the prognosis of patients with high preoperative $\mathrm{HbA} 1 \mathrm{c}$ levels greatly depends on the presence or absence of postoperative complications. To avoid postoperative complications, optimal perioperative management and personalized treatment would be critical, particularly for patients with stage III GC having high preoperative $\mathrm{HbA} 1 \mathrm{c}$ levels.

Acknowledgements The authors would like to thank Enago (www. enago.jp) for the English language review.

\section{Compliance with ethical standards}

Conflicts of interest All authors contributed to the final manuscript, and none of the authors had any conflicts of interest to disclose.

Open Access This article is licensed under a Creative Commons Attribution 4.0 International License, which permits use, sharing, adaptation, distribution and reproduction in any medium or format, as long as you give appropriate credit to the original author(s) and the source, provide a link to the Creative Commons licence, and indicate if changes were made. The images or other third party material in this article are included in the article's Creative Commons licence, unless indicated otherwise in a credit line to the material. If material is not included in the article's Creative Commons licence and your intended use is not permitted by statutory regulation or exceeds the permitted use, you will need to obtain permission directly from the copyright holder. To view a copy of this licence, visit http://creativecommons.org/licenses/by/4.0/.

\section{References}

1. Ferlay J, Soerjomataram I, Dikshit R, Eser S, Mathers C, Rebelo $\mathrm{M}$, et al. Cancer incidence and mortality worldwide: sources, methods and major patterns in GLOBOCAN 2012. Int J Cancer. 2015;136:E359-E386386. https://doi.org/10.1002/ijc.29210.

2. Lazar DC, Avram MF, Romosan I, Cornianu M, Taban S, Goldis A. Prognostic significance of tumor immune microenvironment and immunotherapy: novel insights and future perspectives in gastric cancer. World J Gastroenterol. 2018;24:3583-616. https://doi. org/10.3748/wjg.v24.i32.3583.

3. Miao ZF, Xu H, Xu YY, Wang ZN, Zhao TT, Song YX, et al. Diabetes mellitus and the risk of gastric cancer: a meta-analysis of cohort studies. Oncotarget. 2017;8:44881-92. https://doi. org/10.18632/oncotarget.16487.

4. Tsilidis KK, Kasimis JC, Lopez DS, Ntzani EE, Ioannidis JP. Type 2 diabetes and cancer: umbrella review of meta-analyses of observational studies. BMJ. 2015;350:g7607. https://doi.org/10.1136/ bmj.g7607.

5. Goodenough CJ, Liang MK, Nguyen MT, Nguyen DH, Holihan JL, Alawadi ZM, et al. Preoperative glycosylated hemoglobin and postoperative glucose together predict major complications after abdominal surgery. J Am Coll Surg. 2015;221:854-61. https://doi. org/10.1016/j.jamcollsurg.2015.07.013.

6. Barua R, Templeton AJ, Seruga B, Ocana A, Amir E, Ethier JL. Hyperglycaemia and survival in solid tumours: a systematic review and meta-analysis. Clin Oncol (R Coll Radiol). 2018;30:215-24. https://doi.org/10.1016/j.clon.2018.01.003.

7. Kubota T, Hiki N, Sano T, Nomura S, Nunobe S, Kumagai K, et al. Prognostic significance of complications after curative surgery for gastric cancer. Ann Surg Oncol. 2014;21:891-8. https:// doi.org/10.1245/s10434-013-3384-9.

8. Wang S, Xu L, Wang Q, Li J, Bai B, Li Z, et al. Postoperative complications and prognosis after radical gastrectomy for gastric cancer: a systematic review and meta-analysis of observational studies. World J Surg Oncol. 2019;17:52. https://doi.org/10.1186/ s12957-019-1593-9.

9. Saito T, Kurokawa Y, Miyazaki Y, Makino T, Takahashi T, Yamasaki $\mathrm{M}$, et al. Which is a more reliable indicator of survival after gastric cancer surgery: Postoperative complication occurrence or C-reactive protein elevation? J Surg Oncol. 2015;112:894-9. https ://doi.org/10.1002/jso.24067.

10. Choi YY, Noh SH, An JY. A randomized controlled trial of Roux-en-Y gastrojejunostomy vs. gastroduodenostomy with respect to the improvement of type 2 diabetes mellitus after distal gastrectomy in gastric cancer patients. PLoS ONE. 2017;12:e0188904. https://doi.org/10.1371/journal.pone.01889 04.

11. Schauer PR, Bhatt DL, Kirwan JP, Wolski K, Aminian A, Brethauer SA, et al. Bariatric surgery versus intensive medical therapy for diabetes-5-year outcomes. N Engl J Med. 2017;376:641-51. https://doi.org/10.1056/NEJMoa1600869.

12. Guo W, Zhou Q, Jia Y, Xu J. Increased levels of glycated hemoglobin A1c and iron deficiency anemia: a review. Med Sci Monit. 2019;25:8371-8. https://doi.org/10.12659/MSM.916719.

13. Fiorillo C, Rosa F, Quero G, Menghi R, Doglietto GB, Alfieri $S$. Postoperative hyperglycemia in nondiabetic patients after gastric surgery for cancer: perioperative outcomes. Gastric Cancer. 2017;20:536-42. https://doi.org/10.1007/s10120-016-0621-5.

14. Committee of the Japan Diabetes Society on the Diagnostic Criteria of Diabetes Mellitus, Seino Y, Nanjo K, Tajima N, Kadowaki T, Kashiwagi A, et al. Report of the committee on the classification and diagnostic criteria of diabetes mellitus. J Diabetes Investig. 2010;1:212-28. https://doi.org/10.111 1/j.2040-1124.2010.00074.x.

15. An JY, Kim YM, Yun MA, Jeon BH, Noh SH. Improvement of type 2 diabetes mellitus after gastric cancer surgery: shortterm outcome analysis after gastrectomy. World J Gastroenterol. 2013;19:9410-7. https://doi.org/10.3748/wjg.v19.i48.9410.

16. Cummings DE, Arterburn DE, Westbrook EO, Kuzma JN, Stewart $\mathrm{SD}$, Chan CP, et al. Gastric bypass surgery vs intensive lifestyle and medical intervention for type 2 diabetes: the CROSSROADS randomised controlled trial. Diabetologia. 2016;59:945-53. https ://doi.org/10.1007/s00125-016-3903-x.

17. Gustafsson UO, Thorell A, Soop M, Ljungqvist O, Nygren J. Haemoglobin A1c as a predictor of postoperative hyperglycaemia and complications after major colorectal surgery. Br J Surg. 2009;96:1358-64. https://doi.org/10.1002/bjs.6724.

18. Dindo D, Demartines N, Clavien PA. Classification of surgical complications: a new proposal with evaluation in a cohort of 6336 patients and results of a survey. Ann Surg. 2004;240:205-13. https ://doi.org/10.1097/01.sla.0000133083.54934.ae.

19. Brierley JD, Gospodarowicz MK, Wittekind C. TNM classification of malignant tumours. 8th ed. John Wiley \& Sons, Ltd.; 2017.

20. Dev R, Bruera E, Dalal S. Insulin resistance and body composition in cancer patients. Ann Oncol. 2018;29:ii18-26. https://doi. org/10.1093/annonc/mdx815.

21. Kwon S, Thompson R, Dellinger P, Yanez D, Farrohki E, Flum D. Importance of perioperative glycemic control in general surgery: a report from the Surgical Care and Outcomes Assessment Program. Ann Surg. 2013;257:8-14. https://doi.org/10.1097/SLA.0b013 e31827b6bbc. 
22. Capes SE, Hunt D, Malmberg K, Gerstein HC. Stress hyperglycaemia and increased risk of death after myocardial infarction in patients with and without diabetes: a systematic overview. Lancet. 2000;355:773-8. https://doi.org/10.1016/S0140-6736(99)08415 $-9$.

23. Gale SC, Sicoutris C, Reilly PM, Schwab CW, Gracias VH. Poor glycemic control is associated with increased mortality in critically ill trauma patients. Am Surg. 2007;73:454-60.

24. Kiran RP, Turina M, Hammel J, Fazio V. The clinical significance of an elevated postoperative glucose value in nondiabetic patients after colorectal surgery: evidence for the need for tight glucose control? Ann Surg. 2013;258:599-604. https://doi.org/10.1097/ SLA.0b013e3182a501e3.

25. Chang SC, Yang WV. Hyperglycemia, tumorigenesis, and chronic inflammation. Crit Rev Oncol Hematol. 2016;108:146-53. https ://doi.org/10.1016/j.critrevonc.2016.11.003.

26. McArdle CS, McMillan DC, Hole DJ. Impact of anastomotic leakage on long-term survival of patients undergoing curative resection for colorectal cancer. Br J Surg. 2005;92:1150-4. https://doi. org/10.1002/bjs.5054.

27. Hay N. Reprogramming glucose metabolism in cancer: can it be exploited for cancer therapy? Nat Rev Cancer. 2016;16:635-49. https://doi.org/10.1038/nrc.2016.77.

28. Balkwill F, Mantovani A. Inflammation and cancer: back to Virchow? Lancet. 2001;357:539-45. https://doi.org/10.1016/S0140 -6736(00)04046-0.

29. van Niekerk G, Davis T, Patterton HG, Engelbrecht AM. How does inflammation-induced hyperglycemia cause mitochondrial dysfunction in immune cells? BioEssays. 2019;41:e1800260. https ://doi.org/10.1002/bies.201800260.

30. Dixon JB, Zimmet P, Alberti KG, Rubino F, International Diabetes Federation Taskforce on Epidemiology, and Prevention. Bariatric surgery: an IDF statement for obese Type 2 diabetes. Arq Bras Endocrinol Metabol. 2011;55:367-82.

31. Lee EK, Kim SY, Lee YJ, Kwak MH, Kim HJ, Choi IJ, et al. Improvement of diabetes and hypertension after gastrectomy: a nationwide cohort study. World J Gastroenterol. 2015;21:117381. https://doi.org/10.3748/wjg.v21.i4.1173.

32. Goto A, Noda M, Matsushita Y, Goto M, Kato M, Isogawa A, et al. Hemoglobin A1c levels and the risk of cardiovascular disease in people without known diabetes: a population-based cohort study in Japan. Medicine (Baltimore). 2015;94:e785. https://doi. org/10.1097/MD.0000000000000785.

33. Kochi R, Suzuki T, Yajima S, Oshima Y, Ito M, Funahashi K, et al. Does preoperative low HbA1c predict esophageal cancer outcomes? Ann Thorac Cardiovasc Surg. 2019. https://doi. org/10.5761/atcs.oa.19-00238.

34. Yoo HM, Lee HH, Shim JH, Jeon HM, Park CH, Song KY. Negative impact of leakage on survival of patients undergoing curative resection for advanced gastric cancer. J Surg Oncol. 2011;104:734-40. https://doi.org/10.1002/jso.22045.

35. Fujiya K, Tokunaga M, Mori K, Makuuchi R, Tanizawa Y, Bando $\mathrm{E}$, et al. Long-term survival in patients with postoperative intraabdominal infectious complications after curative gastrectomy for gastric cancer: a propensity score matching analysis. Ann Surg Oncol. 2016;23:809-16. https://doi.org/10.1245/s1043 4-016-5577-5.

36. Zhou J, Zhou Y, Cao S, Li S, Wang H, Niu Z, et al. Multivariate logistic regression analysis of postoperative complications and risk model establishment of gastrectomy for gastric cancer: a single-center cohort report. Scand J Gastroenterol. 2016;51:8-15. https://doi.org/10.3109/00365521.2015.1063153.

37. van den Berghe G, Wouters P, Weekers F, Verwaest C, Bruyninckx F, Schetz M, et al. Intensive insulin therapy in critically ill patients. N Engl J Med. 2001;345:1359-67. https://doi. org/10.1056/NEJMoa011300.

Publisher's Note Springer Nature remains neutral with regard to jurisdictional claims in published maps and institutional affiliations. 